Article

\title{
Antifungal and Antivirulence Activity of Vaginal Lactobacillus Spp. Products against Candida Vaginal Isolates
}

\author{
Camilla Itapary dos Santos ${ }^{1}$, Yasmine Ramos França ${ }^{1}$, Carmem Duarte Lima Campos ${ }^{2}$, \\ Maria Rosa Quaresma Bomfim ${ }^{3}{ }^{\circledR}$, Bruna Oliveira Melo ${ }^{3}$, Rodrigo Assunção Holanda ${ }^{3}$, \\ Vera Lucia Santos ${ }^{4}$, Sílvio Gomes Monteiro ${ }^{5,6} \mathbb{D}^{\mathbb{D}}$, Eduardo Buozzi Moffa ${ }^{2}$, \\ Andrea Souza Monteiro ${ }^{2}$, Cristina Andrade Monteiro ${ }^{2,7, *(\mathbb{D})}$ and Valério Monteiro-Neto ${ }^{2,5}$ (D) \\ 1 Laboratório de Microbiologia Aplicada, Programa de Mestrado em Biologia Parasitária, Universidade Ceuma, \\ São Luís, MA 65075120, Brazil; camilla_itapary@hotmail.com (C.I.d.S.); minyfranca@gmail.com (Y.R.F.) \\ 2 Programa de Mestrado em Biologia Microbiana, Universidade Ceuma, São Luís, MA 65075120, Brazil; \\ carmemcampos01@hotmail.com (C.D.L.C); eduardo.moffa@ceuma.br (E.B.M.); \\ andreasmont@gmail.com (A.S.M.); valerio.monteiro@ceuma.br (V.M.-N.) \\ 3 Laboratório de Biologia Molecular de Microrganismos, Programa de Mestrado em Biologia Microbiana, \\ Universidade Ceuma, São Luís, MA 65075120, Brazil; mrqbomfim@gmail.com (M.R.Q.B); \\ brunaoliv96@gmail.com (B.O.M.); raholanda@yahoo.com.br (R.A.H.) \\ 4 Laboratório de Microbiologia Aplicada, Departamento de Microbiologia, Instituto de Ciências Biológicas, \\ Universidade Federal de Minas Gerais, Belo Horizonte, MG 31270901, Brazil; verabio@gmail.com \\ 5 Centro de Ciências Biológicas e da Saúde, Universidade Federal do Maranhão, São Luís, MA 65080-805, \\ Brazil; silvio_gm@yahoo.com.br \\ 6 Programa de Mestrado em Meio Ambiente, Universidade Ceuma, São Luís, MA 65075120, Brazil \\ 7 Departamento de Biologia, Instituto Federal do Maranhão, São Luís, MA 65030005, Brazil \\ * Correspondence: cristina.monteiro@ceuma.br; Tel.: +55-98-982947406
}

Received: 19 August 2019; Accepted: 7 September 2019; Published: 12 September 2019

\begin{abstract}
Candida yeasts are generally found in the vaginal microbiota; however, disruption of the balance maintained by host factors and microorganisms results in vulvovaginal candidiasis (VVC). This study evaluated the antagonistic activity of vaginal Lactobacillus spp. on Candida albicans to verify whether active compounds of Lactobacillus spp. had antifungal and antivirulence activity. The antagonism assay showed that 15 out of 20 Lactobacillus strains had an inhibitory effect on C. albicans. Biosurfactants displayed surface-tension-reducing activity, with the best value obtained for Lactobacillus gasseri 1. Lactobacillus rhamnosus ATCC 9595, Lactobacillus acidophilus ATCC 4356, and Lactobacillus paracasei 11 produced biosurfactants that decreased C. albicans adhesion and disrupted biofilm formation. The best results were obtained in the pre-incubation assay for L. gasseri 1 and L. paracasei 11. Overall, Lactobacillus strains showed significant anti-Candida activity, and their biosurfactants exhibited considerable anti-adhesion and antibiofilm activity against $C$. albicans. To be considered safe for use in vivo, the safety of biosurfactant (BS) should be investigated using cytotoxicity assays.
\end{abstract}

Keywords: Lactobacillus biosurfactant production; biofilm inhibition; Candida albicans suppression; Lactobacillus antivirulence; vulvovaginal candidiasis

\section{Introduction}

Candida yeasts are generally found in the vaginal microbiota, but their presence does not always lead to the manifestation of symptoms. The complex interactions and synergies among host defense mechanisms and different microorganisms from the vaginal mucosa are responsible for maintaining the balance of the vaginal environment [1]. 
When homeostasis of the vaginal ecosystem is interrupted, overgrowth of Candida yeasts is facilitated and can lead to the development of vulvovaginal candidiasis (VVC) [2]. Primary symptoms of VVC are itching and soreness of the vulva, dysuria, white vaginal discharge, and dyspareunia. VVC can greatly affect the quality of life, in addition to increasing human immunodeficiency virus (HIV) susceptibility [3]. Although VVC is associated with a very low mortality rate, symptoms contribute significantly to morbidity, especially in HIV-infected women. [4]. Furthermore, women with vaginal colonization of Candida spp. during the second trimester of pregnancy have lower neonatal birth weight and higher rates of preterm birth than those colonized during other months of pregnancy [5].

Factors that increase the risk for VVC development include individual susceptibility, frequent sexual intercourse, antibiotic therapy, contraceptive and spermicide use, pregnancy, diabetes, and immunosuppression [3]. VVC is most commonly caused by Candida albicans, but the incidence of VVC caused by other Candida spp. has increased considerably [6-8]. Species, such as Candida glabrata, Candida parapsilosis, Candida krusei, and Candida tropicals are isolated with increasing frequency [7-10]. Increased infections by other Candida spp. have contributed to high rates of recurrence and resistance [10-13].

Lactobacillus spp. are considered normal colonizers of the human body, forming a part of the resident microbiota, and do not damage the host. In healthy vaginal microbiota, Lactobacillus spp. are one of the most abundant microorganisms [14]. Lactobacillus spp. control the excessive multiplication of potential pathogens by producing organic acids and antimicrobial compounds (hydrogen peroxide, bacteriocins, and surface-active compounds, including biosurfactants (BSs)), by auto-aggregation, or by competing for nutrients and adherence sites in the vaginal epithelium [15-17]. However, the pathogenesis of VVC remains a controversial issue. Individual susceptibility (genetics), pregnancy, antibiotic therapy, use of contraceptives and spermicide, frequent sexual intercourse, diabetes, and immunosuppression are factors that increase the risk for development of VVC [2,18].

Microorganisms can synthesize several types of surface-active compounds, including BSs, which have low molecular weights. BSs exhibit surfactant and emulsifying activity, and, therefore, have the ability to decrease the interface between two phases of a heterogeneous system; besides, they are useful as antibacterial, antifungal, anti-adhesive, and antibiofilm agents, and even have potential for use as major immunomodulatory molecules or in vaccines and gene therapy [19].

Probiotics are defined as "live microorganisms that, when administered in adequate amounts, confer a health benefit to the host" [20]. Several studies have reported the potential use of BSs produced by lactic acid bacteria (LAB) in the food and health industries [21-25]. In the food industry, it can be used as a treatment of food-contact surfaces, thus preventing biofilm formation; food additive/ingredient, and in residues treatment [26]. Their potential use in health industries may be related with anti-adhesive properties, which inhibit the adhesion of pathogenic organisms to solid surfaces, such as silicone rubber, surgical implants, and vinyl urethral catheters, or biological surfaces (urogenital and intestinal tract epithelial cells) $[25,27,28]$. Besides, BS may be used in pharmaceutical fields as agents for respiratory failure, immunological adjuvants, recovery of intracellular products, antimicrobial activity, antiviral activity, anticancer activity, and agents for the stimulation of skin fibroblast metabolism [29]. LAB interference in pathogen colonization occurs through multiple mechanisms, including BS production [30].

Surface-active compounds could be an alternative method to interfere with or avoid colonization by pathogenic microorganisms, preventing the progression of infections. Recently, Lactobacillus spp. have attracted the attention of the medical community due to their antagonistic effects against innumerable human pathogens, indicating potential therapeutic or prophylactic use for certain infectious diseases [31,32]. We have recently shown that Lactobacillus fermentum ATCC 23271 displayed antagonistic activity on Candida species in vitro and also inhibited yeast adherence to HeLa cells and mucin [33]. However, the effects and anti-Candida mechanisms of Lactobacillus BSs are still not fully understood, especially those related to resident Lactobacillus spp.

This work aimed to evaluate the antagonistic activity of Lactobacillus spp. from vaginal specimens on C. albicans from healthy women and those with clinical suspicion of VVC, verifying whether the active compounds of Lactobacillus spp., including BSs, have antifungal activities, and whether they 
interfere with the adhesion and biofilm processes of Candida albicans. A major contribution of this work was the identification of natural Lactobacillus species from the microbiota that have probiotic potential against Candida species.

\section{Results}

\subsection{Microbial Isolation and Identification}

Vaginal specimens were collected from 50 patients between 18 and 79 years of age during a colpocytology examination at a public hospital in São Luís, Maranhão, Brazil. From these samples, 16 Candida and 15 Lactobacillus isolates were detected (Table 1). In specimens of certain patients, concomitant detection of Candida and Lactobacillus isolates occurred in the same sample. Six Candida spp. and seven Lactobacillus spp. were isolated from 11 asymptomatic women. C. albicans (50\%) and Lactobacillus gasseri (50\%) were the most prevalent species in this patient group. Ten Candida spp. and eight Lactobacillus spp. were isolated from 14 women with VVC. The most frequent yeasts of the VVC group were C. albicans (50\%) and C. glabrata (50\%), while L. gasseri was the most frequent Lactobacillus species (57\%). There was no difference in the frequency of Candida spp. between asymptomatic patients and those with VVC. The same was observed for Lactobacillus spp. We have adopted molecular identification methods as the standard for yeasts and bacteria.

Table 1. Identification of Candida and Lactobacillus isolates from vaginal microbiota of asymptomatic women (control group) and women with clinical suspicion of VVC from a public hospital in São Luís, Maranhão, Brazil.

\begin{tabular}{|c|c|c|c|c|}
\hline \multirow[t]{2}{*}{ Patient ID } & \multirow[t]{2}{*}{ Condition } & \multirow{2}{*}{$\begin{array}{c}\begin{array}{c}\text { Candida } \\
\text { Identification }\end{array} \\
\text { Multiplex PCR }\end{array}$} & \multicolumn{2}{|l|}{ Lactobacillus Identification } \\
\hline & & & 16S rRNA Sequencing (\% homology) & No. Access \\
\hline V2 & VVC & C. albicans & L. gasseri $(100 \%)$ & MK982449 \\
\hline V3 & & C. glabrata & & \\
\hline V5 & & C. glabrata & & \\
\hline V6 & & C. glabrata & & \\
\hline V8 & & C. albicans & & \\
\hline V10 & & C. glabrata & & \\
\hline V12 & & C. albicans & & \\
\hline V14 & & C. albicans & & \\
\hline V15 & & & L. gasseri $(100 \%)$ & MK982454 \\
\hline V17 & & & L. gasseri $(100 \%)$ & MK982456 \\
\hline V19 & & C. glabrata & L. vaginalis $(99 \%)$ and L. gasseri $(100 \%)$ & $\begin{array}{l}\text { MN019109 } \\
\text { MK982457 }\end{array}$ \\
\hline V21 & & C. albicans & L. vaginalis $(100 \%)$ & MK982458 \\
\hline V23 & & & L. crispatus $(100 \%)$ & MK982461 \\
\hline V24 & & & L. paracasei $(99 \%)$ & MK982460 \\
\hline A1 & Asymptomatic & & L. gasseri $(100 \%)$ & MK982448 \\
\hline A4 & & C. glabrata & L. gasseri $(97.49 \%)$ & MK982450 \\
\hline A7 & & & L. vaginalis (99\%) & MK982451 \\
\hline A9 & & C. albicans & L. rhamnosus (100\%) & MK982452 \\
\hline A11 & & & L. paracasei $(99.37 \%)$ & MK982453 \\
\hline A13 & & C. albicans & & \\
\hline A16 & & & L. gasseri $(100 \%)$ & MK982455 \\
\hline A18 & & C. krusei & & \\
\hline A20 & & C. parapsilosis & & \\
\hline A22 & & & L. gasseri $(100 \%)$ & MK982459 \\
\hline A 25 & & C. albicans & & \\
\hline
\end{tabular}

Legend: VVC, suggestive for vulvovaginal candidiasis; ID = sample identification; YSARGBN locus (Candida albicans 5.8S ribosomal RNA gene, complete, $28 \mathrm{~S}$ ribosomal RNA gene, 5 'end) was used for the identification of $C$. albicans isolates (GenBank: L47111.1), and locus AB032177 (Candida glabrata genes for ITS1, 5.8S rRNA), ITS2) for C. glabrata isolates identification (GenBank: AB032177). 


\subsection{Antagonism Assay}

The antagonism assay showed that 15 of 20 Lactobacillus strains, including the five reference strains, had an inhibitory effect on C. albicans. Growth inhibition zones ranged from 9.5 to $28.5 \mathrm{~mm}$ (Table 2). Among the antagonistic strains, L. acidophilus ATCC 4356, L. rhamnosus ATCC 9595, and the clinical isolate L. paracasei 11 (Lp11) were able to inhibit all Candida studied. Evaluation by Tukey's statistical test showed that the inhibitory ability was dependent upon both the Candida and Lactobacillus strains tested.

Table 2. Antagonism test between Lactobacillus spp. and Candida albicans performed by an overlay technique on Man, Rogosa, and Sharpe (MRS) agar medium. Diameters of inhibition zone values (mm) were measured after $48 \mathrm{~h}$ of incubation. Inhibitory ability was dependent upon both the Candida and Lactobacillus strains tested (Tukey's statistical test).

\begin{tabular}{|c|c|c|c|c|c|c|c|c|}
\hline \multirow{2}{*}{ Lactobacillus $^{1}$} & \multicolumn{8}{|c|}{ Candida albicans Isolates ${ }^{2}$} \\
\hline & $\mathrm{Ca} 2$ & Ca8 & Ca9 & Ca12 & Ca13 & Ca14 & Ca21 & Ca25 \\
\hline L. gasseri V17 & $\mathrm{NZ}$ & NZ & NZ & $13 \pm 0$ & NZ & $\mathrm{NZ}$ & $\mathrm{NZ}$ & $\mathrm{NZ}$ \\
\hline L. vaginalis V19.1 & $10 \pm 0$ & $12 \pm 1.41$ & $12.5 \pm 0.70$ & NZ & $11 \pm 0$ & NZ & NZ & $\mathrm{NZ}$ \\
\hline L. gasseri V19.2 & NZ & NZ & NZ & NZ & $\mathrm{NZ}$ & NZ & NZ & NZ \\
\hline L. vaginalis V21 & $18.5 \pm 2.12$ & NZ & $13.5 \pm 3.53$ & $12.5 \pm 0.70$ & $15.5 \pm 0.70$ & $15.5 \pm 2.12$ & $15.5 \pm 0.70$ & $14.5 \pm 2.12$ \\
\hline L. crispatus V23 & NZ & $13 \pm 1.41$ & $11.5 \pm 0.70$ & NZ & NZ & $\mathrm{NZ}$ & $\mathrm{NZ}$ & $11 \pm 0$ \\
\hline L. paracasei V24 & $9.5 \pm 0.70$ & $13 \pm 1.41$ & $11 \pm 1.41$ & $15 \pm 0$ & $\mathrm{NZ}$ & $13.5 \pm 0.70$ & $\mathrm{NZ}$ & $11 \pm 0$ \\
\hline L. gasseri A1 & $15.5 \pm 0.70$ & NZ & NZ & $10.5 \pm 0.70$ & NZ & $14 \pm 1.41$ & NZ & NZ \\
\hline L. gasseri A4 & NZ & $12.5 \pm 0.70$ & $16 \pm 1.41$ & NZ & $14 \pm 1.41$ & $14 \pm 1.41$ & $\mathrm{NZ}$ & $13.5 \pm 0.70$ \\
\hline L. vaginalis A7 & NZ & $16 \pm 1.41$ & $16 \pm 0$ & $19.5 \pm 2.12$ & $22.5 \pm 3.53$ & $20 \pm 0$ & $17 \pm 1.41$ & $16.5 \pm 4.94$ \\
\hline L. paracasei A11 & $26 \pm 1.41$ & $19.5 \pm 0.7$ & $18.5 \pm 2.12$ & $13.5 \pm 3.53$ & $17 \pm 8.48$ & $21.5 \pm 4.94$ & $19.5 \pm 2.12$ & $16 \pm 1.41$ \\
\hline L. gasseri A16 & NZ & $15.5 \pm 0.70$ & NZ & NZ & $20.5 \pm 2.12$ & $13.5 \pm 0.70$ & $16 \pm 0$ & $11.5 \pm 0.70$ \\
\hline L. gasseri A22 & NZ & NZ & NZ & NZ & $12.5 \pm 0.70$ & NZ & NZ & NZ \\
\hline L. acidophilus ATCC 4356 & $21.5 \pm 2.12$ & $16 \pm 0$ & $13 \pm 1.41$ & $21.5 \pm 2.12$ & $17 \pm 2.82$ & $15.5 \pm 6.36$ & $15.5 \pm 0.70$ & $19.5 \pm 0.70$ \\
\hline L. debrueckii ATCC 9645 & NZ & NZ & NZ & NZ & NZ & $13 \pm 1.41$ & NZ & $11.5 \pm 0.70$ \\
\hline L. fermentum ATCC 23271 & $17 \pm 1.41$ & $16 \pm 1.41$ & $13 \pm 0$ & NZ & $15 \pm 4.24$ & $12 \pm 1.41$ & $12.5 \pm 0.70$ & $14.5 \pm 3.53$ \\
\hline L. paracasei ATCC 335 & $28.5 \pm 2.12$ & $17.5 \pm 0.70$ & $15 \pm 5.65$ & NZ & $17.5 \pm 0.70$ & $17.5 \pm 3.53$ & $15.5 \pm 0.70$ & $16 \pm 1.41$ \\
\hline L. rhamnosus ATCC 9595 & $22.5 \pm 0.70$ & $20 \pm 0$ & $18.5 \pm 0.70$ & $21 \pm 4.24$ & $20 \pm 0$ & $19.5 \pm 0.70$ & $25 \pm 7.07$ & $19.5 \pm 0.70$ \\
\hline
\end{tabular}

The anti-Candida activity of Lactobacillus from asymptomatic women was higher than that of Lactobacillus from patients with suspected VVC (Table $3 ; p<0.05$ ).

Table 3. Independent chi-square test of the proportion of inhibition of Candida isolates by Lactobacillus from patients with clinically suspected VVC and those of asymptomatic women.

\begin{tabular}{cc}
\hline \% Inhibited Candida albicans Isolates \\
\hline VVC & Asymptomatic \\
\hline 12.5 & 37.5 \\
50 & 62.5 \\
0 & 87.5 \\
87.5 & 100 \\
37.5 & 62.5 \\
75 & 12.5 \\
\hline$\%$ means: 43.75 & 60.42 \\
\hline \multicolumn{2}{c}{$\chi^{2}=11.26 p=0.046$} \\
\hline
\end{tabular}

\subsection{BS-Producing Lactobacilli and BS Properties}

BS production was evaluated by the emulsifying activity $\left(E_{24}\right)$. The strains that gave an emulsifying layer after $24 \mathrm{~h}$ were considered to be BS producers. Among the 20 Lactobacillus samples tested, four reference strains and three clinical isolates were BS producers by using hexane (Figure 1A). The following BS properties were evaluated: emulsification activity, dry weight, $\mathrm{OD}_{640}$ measurements, and drop collapse test. 


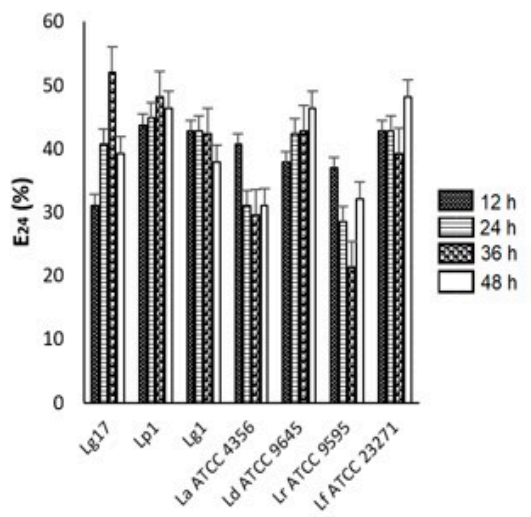

(A)

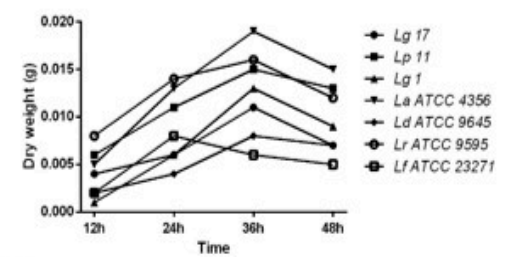

(C)

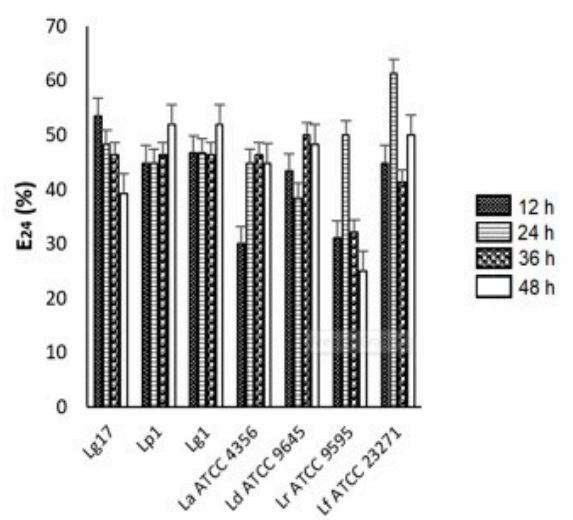

(B)

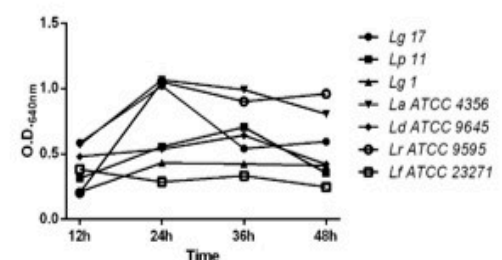

(D)

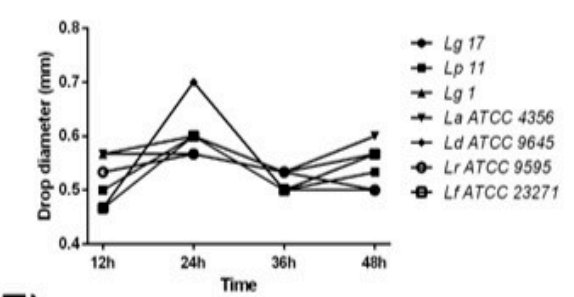

(E)

Figure 1. Emulsification activities, shown by Lactobacillus spp., produced biosurfactants expressed as an emulsification index $\left(\mathrm{E}_{24}\right)$ and biosurfactants' dry-weight measurement, biomass concentration, and drop-collapse assay. (A) Emulsification indices $\left(E_{24 \%}\right)$ evaluated using hexane as the organic phase. (B) Emulsification indices $\left(\mathrm{E}_{24 \%}\right.$ ) evaluated using toluene as the organic phase. (C) Dry-weight measurement (g). (D) Biomass concentration $\left(\mathrm{OD}_{640 \mathrm{~nm}}\right)$ of biosurfactants. (E) Biosurfactant drop-collapse assay. Results are shown over time $(12,24,36$, and $48 \mathrm{~h})$ and represent the average of three independent experiments. Lg_Lactobacillus gasseri; Lp_Lactobacillus paracasei; La_Lactobacillus acidophilus; Ld-Lactobacillus debrueckii; Lr_Lactobacillus rhamnosus; Lf-Lactobacillus fermentum. Letter (B): $p<0.05$, in relation to hexane; $p>0.05$, in relation to incubation time.

The emulsifying activity, designated as the emulsification index $\left(\mathrm{E}_{24}\right)$, was evaluated using toluene or hexane as an organic solvent. According to the hydrophobic substrates evaluated, $\mathrm{E}_{24}$ values varied by Lactobacillus BS. In general, higher $\mathrm{E}_{24}$ values were obtained using toluene $(p<0.05)$ (Figure 1B). The highest $\mathrm{E}_{24}$ value ( $53 \%$ in $12 \mathrm{~h}$ ), among vaginal Lactobacillus isolates, was obtained by Lg17 (Lactobacillus gasseri 17) in the presence of toluene (Figure 1B). The BS produced by Lp11 (Lactobacillus paracasei 11) and Lg1 only emulsified toluene solvent at values greater than $50 \%$ in $48 \mathrm{~h}$ (Figure 1B). There were no significant differences in BS production by any species in relation to time $(p>0.05)$. Using hexane, $\operatorname{Lg} 17$ reached an $\mathrm{E}_{24}$ of $52 \%$ in $36 \mathrm{~h}$ of fermentation. Lp11 and $\operatorname{Lg} 1$ had $\mathrm{E}_{24}$ values under $50 \%$ in all incubation times (Figure 1A). For the reference strains, the highest $\mathrm{E}_{24}$ toluene values of $50 \%$ and 61.2\% were obtained for L. rhamnosus ATCC 9595 and L. fermentum ATCC 23271, respectively, in $24 \mathrm{~h}$ of fermentation (Figure 1B). An $\mathrm{E}_{24}$ value of $50 \%$ for L. debrueckii ATCC 9645 was only obtained by $36 \mathrm{~h}$ of incubation. In the presence of hexane, all $\mathrm{E}_{24}$ values were under $50 \%$ for every strain, with emulsifying indices from $31 \%$ to $48 \%$. The $\mathrm{E}_{24}$ values for L. rhamnosus ATCC 9595 and L. acidophilus 
ATCC 4356 were smaller at most fermentation times in the presence of any solvents used (Figure 1A,B). The $\mathrm{E}_{24}$ toluene value of $L$. rhamnosus ATCC 9595 was smaller than the other reference strains $(p<0.05)$ (Figure 1B).

Depending on the isolate incubation time, dry-weight values varied significantly $(p<0.05)$. All samples showed a dry-weight gain up to $36 \mathrm{~h}$, followed by a decline, except for L. fermentum ATCC 23271, which began to decline after $24 \mathrm{~h}$. Regarding the reference strains, L. rhamnosus ATCC 9595 had a significantly higher dry-weight measurement in relation to L. acidophilus ATCC 4356, but production did not differ in relation to L. debrueckii ATCC 9645 or L. fermentum ATCC 23271 (Figure 1C). Among clinical samples, $\operatorname{Lg} 1$ had a significantly higher dry weight in relation to the other strains $(p<0.05)$ but did not differ in relation to the reference samples (Figure 1C).

Regarding incubation time, OD values for the different Lactobacillus strains varied significantly $(p<0.05)$. OD quantification showed that Lg1, Lg17, L. rhamnosus ATCC 9595, and L. acidophilus ATCC 4356 presented higher values in the first $24 \mathrm{~h}$, which declined shortly after. $\mathrm{Lg} 1$ values remained nearly stable after the first $24 \mathrm{~h}$. Lp11, L. debrueckii ATCC 9645, and L. fermentum ATCC 23271 showed higher OD values at $36 \mathrm{~h}$ (Figure 1D). All BS droplets resulted in a collapsed droplet in the drop-collapse test. Higher values were obtained in $24 \mathrm{~h}$, and L. debrueckii ATCC 9645 had the highest value $(0.7 \mathrm{~cm})$ (Figure 1E).

\subsection{Surface Tension Determination}

Considering the surface tension (ST) value for PBS, all Lactobacillus strains showed ST-reducing activity. Table 4 shows ST values $(\mathrm{mN} / \mathrm{m})$ of different Lactobacillus-derived BSs. PBS ST was $71.9 \mathrm{mN} / \mathrm{m}$. The highest ST reduction was obtained by Lg1, which reduced the value from $70.9 \mathrm{mN} / \mathrm{m}$ (PBS) to $49.7 \mathrm{mN} / \mathrm{m}$.

Table 4. Surface tension values $(\mathrm{mN} / \mathrm{m})$ of biosurfactant with different Lactobacillus strains grown in MRS medium at $37^{\circ} \mathrm{C}$. Surface tension values were measured in PBS (Phosphate-buffered Saline) after biosurfactant recovery. The surface tension of PBS was $71.9 \pm 0.1 \mathrm{mN} / \mathrm{m}$. Results represent the average of three independent experiments \pm standard deviation.

\begin{tabular}{cc}
\hline Microorganisms & Surface Tension $(\mathbf{m N} / \mathbf{m}) \pm$ Standard Deviation \\
\hline L. gasseri 17 & $52.25 \pm 0.10$ \\
L. paracasei 11 & $55.25 \pm 0.07$ \\
L. gasseri 1 & $49.34 \pm 0.09$ \\
L. acidophilus ATCC 4356 & $61.79 \pm 0.17$ \\
L. delbrueckii ATCC 9645 & $64.46 \pm 0.06$ \\
L. rhamnosus ATCC 9595 & $64.99 \pm 0.06$ \\
L. fermentum ATCC 23271 & $53.85 \pm 0.14$ \\
PBS & $71.90 \pm 0.10$ \\
\hline
\end{tabular}

\subsection{BS Interference on C. albicans Adhesion}

BSs of reference strains L. rhamnosus ATCC 9595 and L. acidophilus ATCC 4356 were able to decrease the adhesion of most Candida studied (78\%). However, interference was significant in the Ca9 and Ca12 isolates $(p<0.05)$ with inhibition values of $42 \%$ and $36 \%$, respectively. BSs of $L$. debrueckii ATCC 9645 and L. fermentum ATCC 23271 decreased the adhesion of three Candida isolates, with the latter interfering significantly in adhesion of the Ca12 isolate (Figure 2A). Lg1 BSs decreased the adhesion in $67 \%$ of Candida isolates. The BSs of Lp11 and Lg17 isolates decreased the adhesion of four and three Candida isolates, respectively (Figure 2B). The interference of both Lg1 and Lg17 were significant in relation to the Ca9 isolate (43\% reduction). All BSs decreased the adhesion process of the Ca12 isolate, whereas $67 \%$ of BSs decreased the adhesion of $\mathrm{Ca} 9$ and Ca14 isolates. 


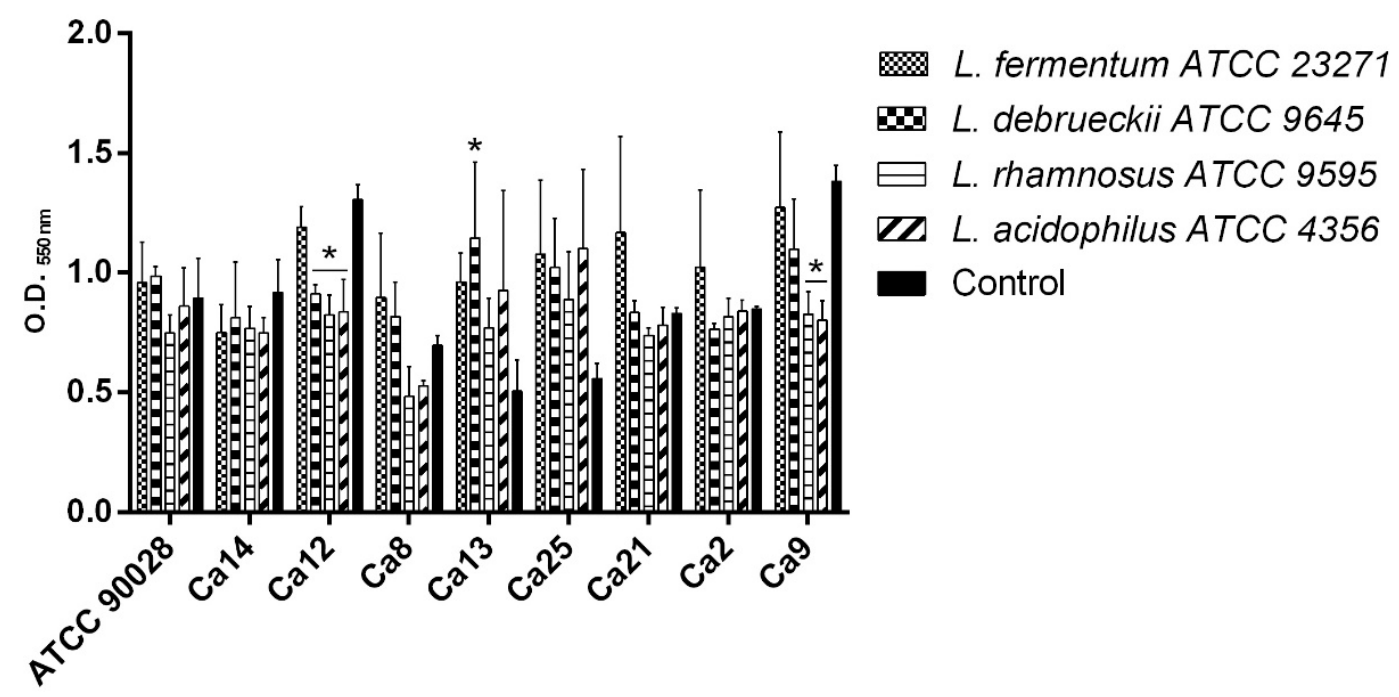

(A)

Candida albicans strains

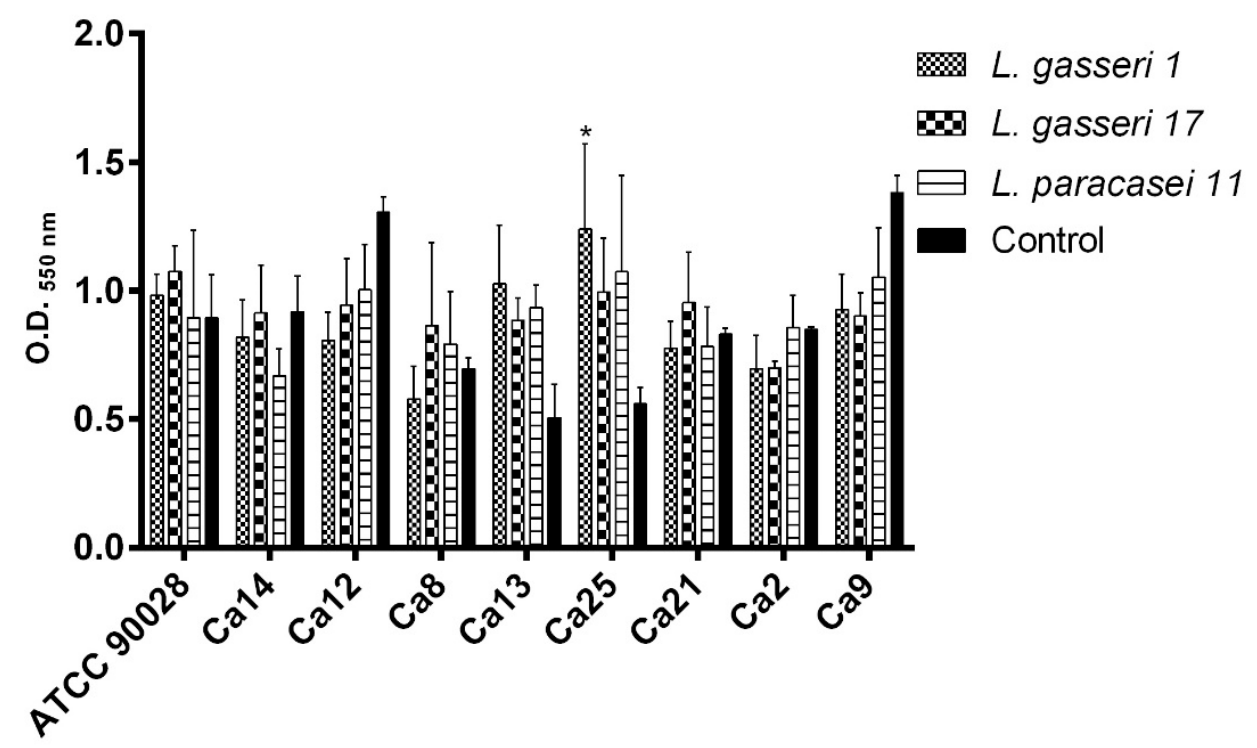

Candida albicans strains

(B)

Figure 2. Interference of Lactobacillus biosurfactants on Candida adhesion to polystyrene. (A) Lactobacillus reference strain biosurfactants. (B) Biosurfactants of vaginal Lactobacillus. The results were expressed as absorbance values at $\mathrm{OD}_{550 \mathrm{~nm}}$ and compared to adhesion without Lactobacillus biosurfactants (control value). Statistical significance was determined at $p<0.05$ * Ca-Candida albicans.

All BSs, except those of Lp11, increased the adhesion of Ca13 and Ca25 isolates in relation to the control. BS from L. fermentum ATCC 23271 also increased the adhesion capacity of C. albicans isolates ATCC 90028, Ca8, Ca21, and Ca2. The product of L. debrueckii ATCC 9645 also enhanced the adhesion of C. albicans ATCC 90028 and Ca8. BS from the clinical isolate Lg17 increased the adhesion of C. albicans ATCC 90028, Ca8, and Ca21.

\subsection{C. albicans Biofilm Formation Ability}

Quantification of the biofilm formation of $C$. albicans isolates by the crystal violet method revealed that all the isolates tested were strong biofilm producers (Figure 3). However, biofilm formation ability varied by strain. C. albicans $\mathrm{Ca} 8$ displayed the highest biofilm formation capacity, with a mean $\mathrm{OD}_{550 \mathrm{~nm}}$ 
value of 2.823. On the other hand, C. albicans $\mathrm{Ca} 2$ strain had the lowest mean $\mathrm{OD}_{550 \mathrm{~nm}}$ value of 1.523 . These strains gave statistically different values to the reference strain, C. albicans ATCC 90028, which had an $\mathrm{OD}_{550 \mathrm{~nm}}$ value of 2.111 .

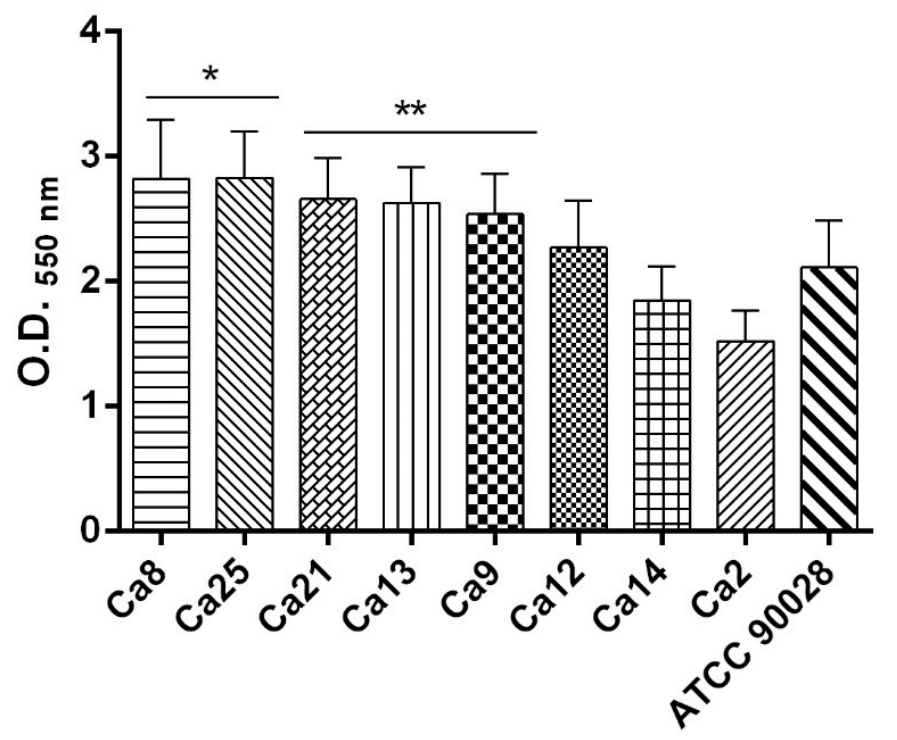

Figure 3. Biofilm formation by C. albicans isolates evaluated in YNB (Yeast Nitrogen Base) culture medium supplemented with $100 \mathrm{mM}$ glucose during a $48 \mathrm{~h}$ period. Biofilm mass was quantified by the crystal violet staining method. Results are expressed as absorbance values at $\mathrm{OD}_{550 \mathrm{~nm}}$. Ca-Candida albicans. Symbols * and ${ }^{* *}$ means statistically different values in relation to the reference strain C. albicans ATCC $90028(p<0.05)$.

\subsection{BS Interference in the Biofilm Formation of C. albicans Isolates}

\subsubsection{Co-Incubation Assay}

BSs produced by Lactobacillus reference strains inhibited biofilm formation of all clinical Candida isolates at different levels. The most efficient BSs were those produced by L. rhamnosus ATCC 9595 and L. acidophilus ATCC 4356, which decreased biofilm formation by $30 \%$ and $35 \%$, respectively (Figure 4 A). The BSs produced by the three clinical Lactobacillus strains were also able to inhibit $C$. albicans biofilms at varying levels, depending on the isolate. The BSs produced by Lg1 and Lp11 were the most efficient, reaching reduction values of $25 \%$ and $28 \%$, respectively (Figure $4 \mathrm{~B}$ ).

\subsubsection{Pre-Incubation Assay}

In the pre-incubation assay, the microplates were previously sensitized with BS. All BSs produced by the reference and clinical Lactobacillus strains were able to decrease biofilm formation of the tested C. albicans strains at varying levels (Figure 5). In this study, the most efficient BSs were those of $L$. rhamnosus ATCC 9595, which reached $44 \%$ and 50\% biofilm formation reduction in Ca13 and Ca8, respectively, and L. fermentum ATCC 23271, which reached $40 \%$ and $47 \%$ reduction against Ca23 and Ca8, respectively. Among the clinical Lactobacillus-produced BSs, Lg1 and Lp11 decreased the biofilm formation of all Candida strains. Lg1 and Lp11 BSs decreased the biofilm of C. albicans Ca8 by $46 \%$ and $41 \%$, respectively (Figure $5 B$ ). 


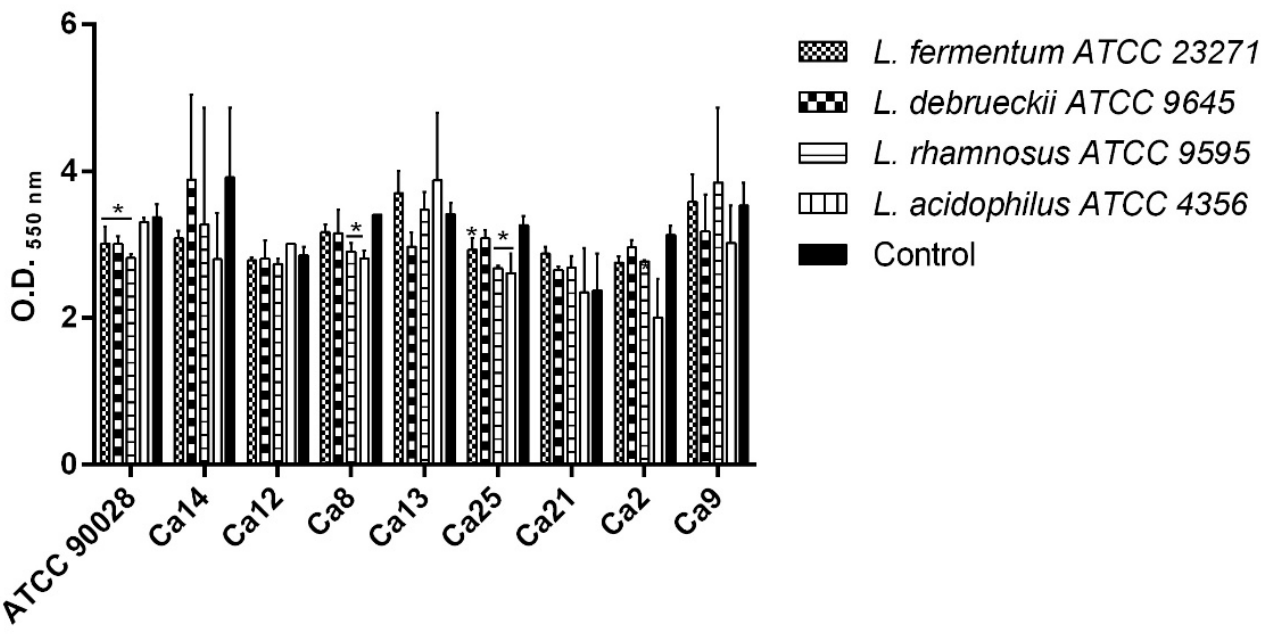

(A)

Candida albicans strains

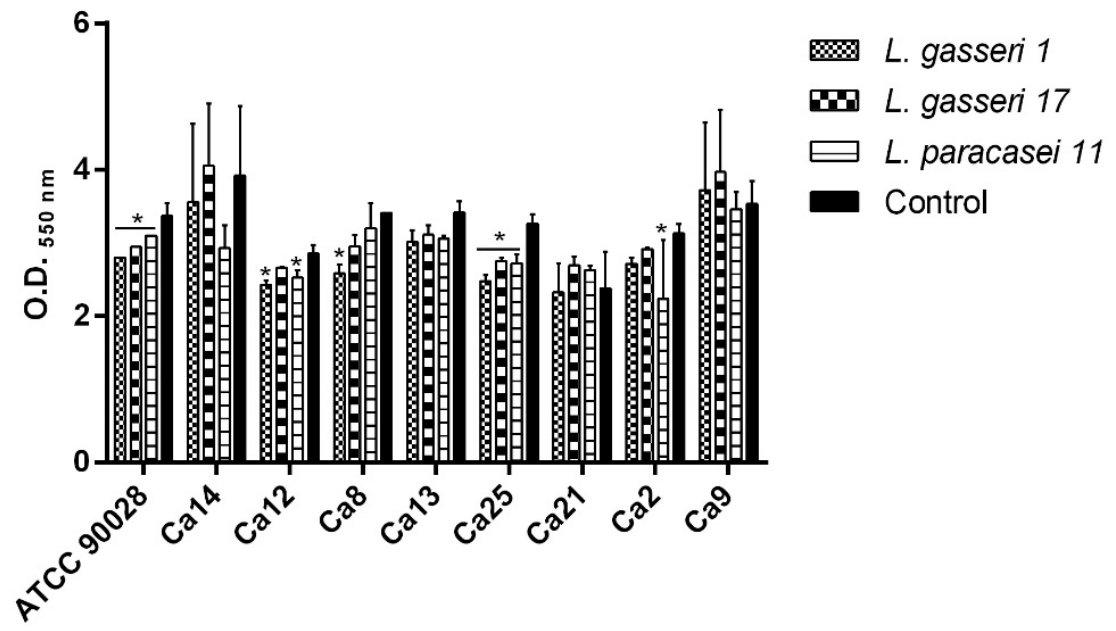

(B)

Candida albicans strains

Figure 4. The effect of Lactobacillus-derived biosurfactants on C. albicans biofilms by the co-incubation assay. (A) Lactobacillus reference strains. (B) Lactobacillus clinical isolates. Results are shown as the optical density of the biofilm mass at $550 \mathrm{~nm}$ and represent the mean and standard deviation (error bars) of three independent experiments. ${ }^{*} p<0.05$ for comparison between the untreated and treated groups. Ca-Candida albicans. 


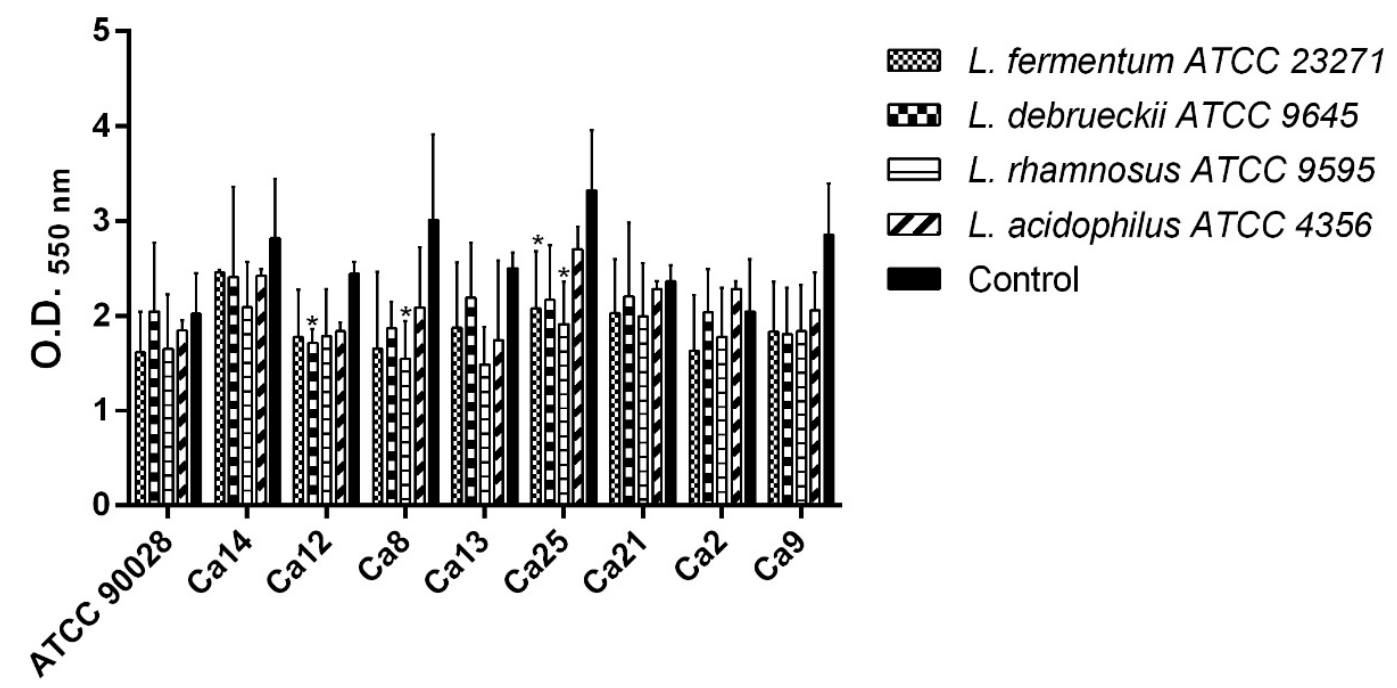

\section{Candida albicans strains}

(A)

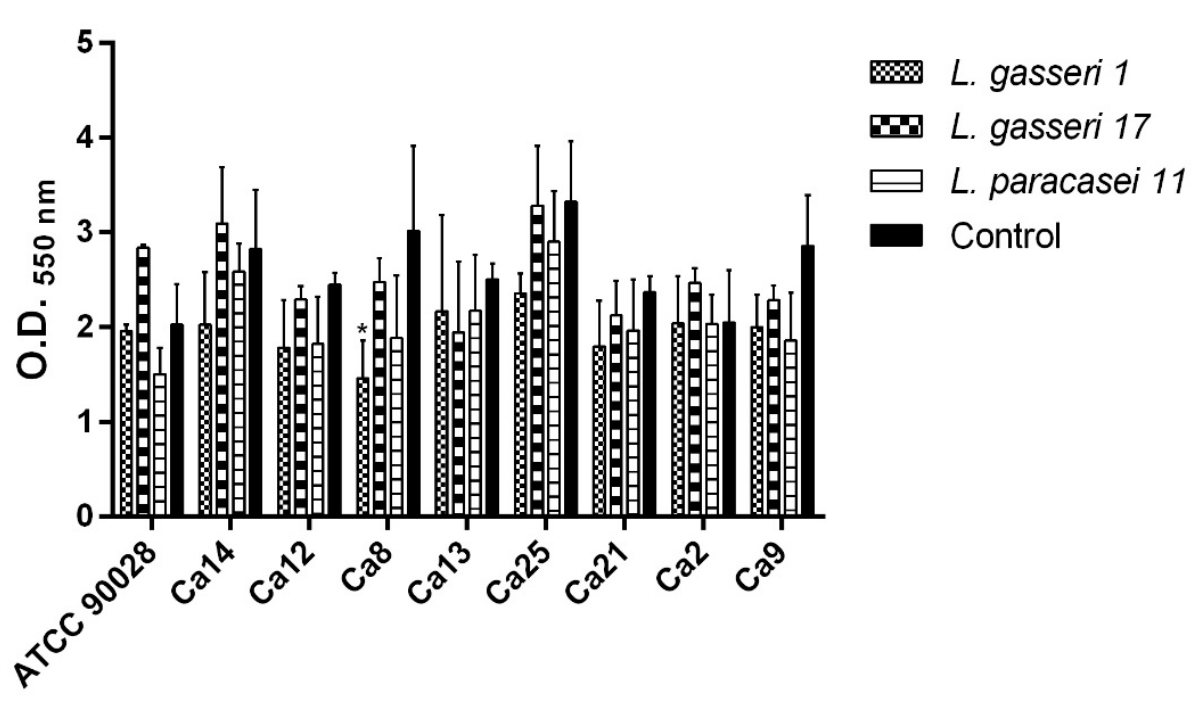

\section{Candida albicans strains}

(B)

Figure 5. The effect of Lactobacillus-derived biosurfactant on Candida albicans biofilm by pre-incubation assay. (A) Lactobacillus reference strains. (B) Lactobacillus clinical isolates. Results are shown as absorbance values of the biofilm mass at $550 \mathrm{~nm}$ and represent the mean and standard deviation (error bars) of three independent experiments. ${ }^{*} p<0.05$ for comparison between the untreated and treated groups. Ca-Candida albicans.

Table 5 summarizes the results obtained for BS-producing Lactobacillus strains regarding the properties and potential of their BS. Lactobacillus from asymptomatic women had greater anti-adhesive and antibiofilm effects than Lactobacillus from a patient with clinically suspected VVC. 
Table 5. Principal properties and potential of biosurfactants produced by vaginal and reference Lactobacillus strains against Candida spp. Emulsification index ( $\mathrm{E}_{24}$ ), Optical density (OD), and dry-weight values are those obtained within $48 \mathrm{~h}$ of experimentation.

\begin{tabular}{|c|c|c|c|c|c|c|c|c|c|}
\hline \multicolumn{10}{|c|}{ Biosurfactant Properties } \\
\hline Lactobacillus & $\begin{array}{l}\text { Patients } \\
\text { Groups }\end{array}$ & $\begin{array}{c}\text { Ability to Inhibit } \\
\text { Candida Growth } \\
\text { (Antagonism Test; \%) }\end{array}$ & $\mathrm{E}_{24}$ & Dry Weight & $\mathrm{OD}_{640 \mathrm{~nm}}$ & ST & $\begin{array}{c}\text { Ability to Inhibit } \\
\text { Candida Adhesion (\%) }\end{array}$ & $\begin{array}{c}\text { Ability to Inhibit } \\
\text { Candida Biofilm } \\
\text { (Pre-Coating Assay; \%) }\end{array}$ & $\begin{array}{c}\text { Ability to Inhibit Candida } \\
\text { Biofilm (Co-Incubation } \\
\text { Assay; \%) } \\
\end{array}$ \\
\hline $\begin{array}{l}\text { L. acidophilus } \\
\text { ATCC } 4356\end{array}$ & - & 100 & 44.80 & 0.015 & 2.028 & 61.79 & 78 & 89 & 67 \\
\hline $\begin{array}{l}\text { L. debrueckii } \\
\text { ATCC } 9645\end{array}$ & - & 25 & 48.20 & 0.007 & 1.985 & 64.46 & 44 & 78 & 78 \\
\hline $\begin{array}{l}\text { L. fermentum } \\
\text { ATCC } 23271\end{array}$ & - & 87.5 & 50 & 0.005 & 1.898 & 53.85 & 33 & 100 & 67 \\
\hline $\begin{array}{l}\text { L. rhamnosus } \\
\text { ATCC } 9595\end{array}$ & - & 100 & 25 & 0.012 & 2.060 & 64.99 & 78 & 100 & 67 \\
\hline L. paracasei 11 & Asymptomatic & 100 & 51.80 & 0.009 & 2.026 & 35.25 & 44 & 89 & 89 \\
\hline L. gasseri 1 & Asymptomatic & 37.5 & 51.80 & 0.013 & 1.970 & 49.34 & 67 & 89 & 89 \\
\hline L. gasseri 17 & VVC & 12.5 & 39.20 & 0.007 & 2.033 & 52.25 & 22.2 & 67 & 67 \\
\hline
\end{tabular}

Legend: VVC: vulvovaginal candidiasis; $\mathrm{E}_{24}$ : emulsification index in the presence of toluene; OD: optical density; $\mathrm{ST}$ : surface tension values (mN/m). 


\subsection{Antifungal Susceptibility Testing}

The susceptibility profile was determined only for clinical isolates of $\mathrm{C}$. albicans, which was the most frequent species. Of the nine clinical isolates, five (55.6\%) were considered $\mathrm{S}$ to fluconazole (FLC), while four (44.4\%) strains had a minimum inhibitory concentration (MIC) of 16 or $32 \mu \mathrm{g} / \mathrm{mL}$. Regarding itraconazole (ITC), only two $(22.2 \%)$ were considered S, and four $(44.4 \%)$ were dose-dependently susceptible (DDS). All isolates were considered susceptible to amphotericin B (AMB). The reference strain (C. albicans ATCC 90028), used as a control, was susceptible to all antifungal agents (Table 6).

Table 6. Minimum inhibitory concentration (MIC) of C. albicans isolates from vaginal secretion samples of vulvovaginitis and asymptomatic women (control) groups from a public hospital in São Luís, Maranhão, Brazil.

\begin{tabular}{cccccc}
\hline \multirow{2}{*}{$\begin{array}{c}\text { PATIENTS } \\
\text { GROUPS }\end{array}$} & STRAINS & \multirow{2}{*}{ SPECIES } & \multicolumn{3}{c}{ MIC $_{\mathbf{1 0 0}}(\boldsymbol{\mu g} / \mathbf{m L})$} \\
\cline { 4 - 6 } & & & FLC & ITC & AMB \\
\hline VVC & Ca2 & C. albicans & 8 & 0.5 & 1 \\
& Ca8 & & 16 & 8 & 0.5 \\
& Ca12 & & 4 & 0.5 & 0.25 \\
& Ca14 & & 8 & 0.062 & 0.5 \\
Control & Ca21 & & 8 & 0.125 & 0.5 \\
& Ca9 & C. albicans & 8 & 1 & 0.5 \\
& Ca13 & & 16 & 8 & 1 \\
& Ca25 & & 16 & 0.25 & 0.5 \\
& Ca18 & & 32 & 0.25 & 1 \\
& ATCC 90028 & C. albicans & 2 & 0.5 & 0.5 \\
\hline
\end{tabular}

Legend: VVC, vulvovaginitis group; MIC, minimum inhibitory concentration; Ca, Candida albicans; FLC, fluconazole; ITC, itraconazole; AMB, amphotericin B. FLC MIC values $\leq 8 \mu \mathrm{g} / \mathrm{mL}$ were considered susceptible (S), 16-32 $\mu \mathrm{g} / \mathrm{mL}$ were considered dose-dependently susceptible (DDS), and $\geq 64 \mu \mathrm{g} / \mathrm{mL}$ were considered resistant (R). For AMB, MICs $\leq 1 \mu \mathrm{g} / \mathrm{mL}$ were considered $\mathrm{S}$ and $>1 \mu \mathrm{g} / \mathrm{mL}$ were considered R. For ITC, MICs $\leq 0.125 \mu \mathrm{g} / \mathrm{mL}$ were considered $\mathrm{S}, 0.25-0.5 \mu \mathrm{g} / \mathrm{mL}$ were considered DDS, and $\geq 1 \mu \mathrm{g} / \mathrm{mL}$ were considered $\mathrm{R}$.

\section{Discussion}

Lactobacillus species are responsible for maintaining a healthy vaginal environment, providing a barrier to the colonization of pathogenic organisms, and inhibiting the exacerbated growth of commensal microorganisms [17]. In the present study, some strains of Lactobacillus showed antagonistic and antivirulence activity against $C$. albicans, including reference strains and clinical isolates. Among these strains, L. acidophilus ATCC 4356, L. rhamnosus ATCC 9595, and the clinical isolate Lp11 were able to inhibit all C. albicans strains tested. This preliminary analysis demonstrated an antifungal activity that might be due to one of the compounds produced by Lactobacillus spp. In vitro studies have reported the antimicrobial potential of Lactobacillus spp. against Candida [2,31,32,34-36]. Probiotics, including those of the genus Lactobacillus, exert antimicrobial activity through the production of various substances, such as organic acids, hydrogen peroxide, bacteriocins, antimicrobial molecules, and BSs-all of which can prevent the growth of potential pathogens $[15,37]$.

Since probiotic LAB can produce BSs that yield in vivo defense properties against pathogen colonization, the ability of Lactobacillus isolates to produce BSs were verified. The emulsifying activity $\left(\mathrm{E}_{24}\right)$, monitored during Lactobacillus growth in MRS broth, was used to determine BS production. Seven Lactobacillus strains were considered BS producers, three clinical isolates (Lg1, Lp11, and Lg17) and four reference strains (L. fermentum ATCC 23271, L. rhamnosus ATCC 9595, L. debrueckii ATCC 9645, and L. acidophilus ATCC 4356). Some of the emulsifying indexes were as high as those found by other authors for BS produced by other Lactobacillus species [34,35].

Different emulsification activities were obtained depending on the concentration of BSs produced and the hydrophobic substrates used in the assays. The emulsifying activity can vary depending on the organic phase chemical structure of both the BS and the emulsion [38]. Most BSs showed substrate specificity, presenting different rates of solubilization or emulsification of different hydrocarbons. 
In this work, emulsifying indices from $31 \%$ to $48 \%$ were obtained with hexane for the Lactobacillus strains that produced BSs. These index values were much smaller when compared to those obtained for the same strains against toluene. BS production in the presence of toluene as a hydrocarbon implies that the BS-producing strain utilizes various toluene components as substrates for BS production [39], thus obtaining higher concentrations of BS [40]. This shows that the choice of solvent is important for obtaining BSs with efficient emulsification properties, which are critical for promising BSs and their applications [25]. This BS-substrate specificity was also observed by other authors [34,38,41]. Besides, all BSs produced by Lactobacillus strains showed good ST reducing activity. BSs decreased PBS ST from 70.91 to $49.34-64.99 \mathrm{mN} / \mathrm{m}$. The highest ST reduction was obtained for Lg1. ST acted as an indicator of surface-related properties of surfactants, such as washability and wetting. Besides, the potential of a microbial surfactant is determined by its ability to reduce the surface tension of a production medium. The ability of a biosurfactant to reduce surface and interfacial tensions determines its functionality and effectiveness. Isolates capable of reducing the ST of distilled water from 72 to $35 \mathrm{mN} / \mathrm{m}$, or of the medium to $\leq 35 \mathrm{mN} / \mathrm{m}$, can be considered strong biosurfactant-producing microbes $[25,39]$.

Currently, BSs are widely used in industrial applications, mainly in heavy metal removal from contaminated soil [41] or crude oil recovery [42]. However, due to surfactant action at interfaces that modify hydrophobic characteristics, BSs have a potential role in preventing microorganism-related diseases, and, therefore, could significantly impact public health [43]. For example, medical instruments made of silicone latex or inox have highly hydrophobic, easily colonized surfaces that favor the formation of biofilms by pathogens, such as yeasts [44]. Additionally, bacterial and yeast strains have demonstrated the ability to colonize hydrophobic silicone rubber surfaces [45]. Application of Lactobacillus BSs could disturb microbial adhesion and desorption processes by interfering with hydrophobicity [25]. Our results support these applications.

Some BSs, such as sophorolipids, have also been used for skin treatment, acting as agents for fibrinolysis, desquamation, depigmentation, and macrophage activation [46]. Rhamnolipids, another kind of BS, are used in low concentrations $(0.1 \%)$ for the treatment of ulcers and burns [47,48]. Although we do not have preliminary information regarding the chemical nature of the BSs tested in our study, the results suggested that the BSs might have similar uses; however, further research is necessary to confirm this and the composition of the BSs to be used.

The scientific world possesses little knowledge regarding the chemical nature of Lactobacillus BS, but research has already reported extensive variability within this compound group $[19,38,40]$. For instance, Rodrigues et al. [19] verified that Lactococcus lactis produced BSs composed of glycoproteins with glucose, rhamnose, fucose, and mannose. Morais et al. [38] found a great percentage of galactose and glucose in the chemical composition of L. jensenii $_{6 \mathrm{~A}}$ and L. gasseri $\mathrm{P}_{65}$. BS diversity in chemical structure (hydrocarbon composition) and carbohydrate, protein, and lipid concentrations may explain the interference variations observed between BSs on the adhesion ability of Candida in this study.

Assays to verify the inhibition potential of BSs on adhesion and biofilm formation showed that they were able to decrease the adhesion of the C. albicans strains tested, highlighting the reference strains L. rhamnosus ATCC 9595 and L. acidophilus ATCC 4356 and the clinical isolate Lp11. Some BSs, such as L. debrueckii ATCC 9645, showed both negative and positive interference in the adhesion processes of Candida isolates. Studies suggest that BSs interfere with biofilm formation, modulating surface interaction, and inhibiting the adhesion process. As previously mentioned, BSs can adsorb to surfaces by reorienting polar and nonpolar groups according to the hydrophobicity of the surface. This interaction between BSs and surface substrates alters the surface hydrophobicity, thereby intensifying or reducing the surface adhesion ability of Candida spp. [22]. The results obtained here, especially those in the pre-incubation assay, support this property of BSs. In this way, the in vitro model of adherence and biofilm formation used in this study were very informative in relation to understanding BS antibiofilm activity. Lactobacillus BSs from both reference and clinical strains disrupted the biofilm of all tested microorganisms at different levels in the co-incubation experiment. However, the best results were obtained in the pre-incubation assay, in which the microplate was previously sensitized with BSs, 
and all BS produced by reference and clinical strains of Lactobacillus were able to decrease the biofilm formation of the tested C. albicans strains to a high degree. For instance, the BS of L. rhamnosus ATCC 9595 reached values of $44 \%$ and 50\% reduction in biofilm formation of Ca13 and Ca8, respectively. $L$. fermentum ATCC 23271 reached $40 \%$ and $47 \%$ reduction against Ca23 and Ca8, respectively. Among the clinical lactobacilli, Lg1 BS was able to decrease C. albicans Ca8 biofilm by $46 \%$, and Lp11 achieved an inhibition percentage of $41 \%$ against the Ca8 isolate. The interference of L. acidophilus ATCC 4356 in the formation of C. albicans biofilm had previously been demonstrated by Vilela et al. [49]. These authors observed that filtered supernatant from a culture of L. acidophilus ATCC 4356 cells was able to inhibit the biofilm formation of C. albicans ATCC 18804.

Our data showed that Lp11 was the clinical isolate that displayed the best anti-Candida activity, although this property could not be attributed to BS alone, even though Lp11 showed the best emulsification index and ST value. Certainly, the anti-Candida activity shown by Lp 11 was due to another compound or to a synergistic combinatory action of several compounds, including BS. Furthermore, the results showed that the action of BS was most likely related to the anti-adhesive and anti-biofilm action against Candida.

LAB interfere in the colonization of pathogens through several mechanisms. The competition for adhesion sites, together with the secretion of BSs, is a well-known mechanism to hinder the establishment of vaginal pathogens [22,50]. The reduction of pathogen colonization to surfaces through the use of BSs produced by LAB has been described for several surfaces, including metal [46], silicone and voice prostheses [21,22,51], and glass [51], as well as other surfaces [23,52]. Results demonstrating the antibiofilm activities of Lactobacillus BSs support the use of BSs as a protective film for the surfaces of hospital devices, such as catheters, to prevent contamination or Candida infection. Taking the results as a whole, as Lg1 and Lg17 showed lower anti-Candida activity, their effects appear to be more associated with anti-adhesive and anti-biofilm activities. In contrast, Lp11 shows excellent anti-Candida activity, although our findings indicated that other compounds besides BS would probably be involved in this function and that Lp11 BS would have greater involvement in the anti-biofilm activity.

Taking into account the anti-adhesion and antibiofilm activities presented by BS and data from the scientific literature $[19,38]$, different types of carbohydrates or certain proteins could contribute to the chemical composition of these Lactobacillus-produced biosurfactants. Our results also drew attention to the possibility of intravaginal administration of pharmaceutical formulations containing BS for prevention or treatment of vaginal Candida infections. This study provided useful insights into the potential uses and applications of BSs; however, BSs need to be purified and characterized due to their varied compositions for an improved understanding of their anti-Candida and antivirulence activity. To be considered safe for use in vivo, the safety of BS should be investigated by using cytotoxicity assays.

VVC is often difficult to treat and is recurrent in most cases [13]. In this context, the drug susceptibility assays revealed that many Candida isolates of this study were considered DDS or R to ITC $(77.7 \%)$ and FLC (44.4\%). These findings point to a phenomenon of increased resistance against conventional antifungal drugs and reiterate the need to identify new potential alternatives against these pathogens.

\section{Materials and Methods}

\subsection{Patients and Ethical Aspects}

The Ethics Committee of the CEUMA University approved the research protocols (number 813.402/2014), and all methods were performed per the relevant guidelines and regulations. Samples were collected from 50 patients at the Hospital da Mulher, São Luís, Maranhão, Brazil, during preventive tests for cervical cancer, after signing an informed consent form. Informed consent was obtained from all subjects. The exclusion criteria included women who had used antifungal medication (oral and/or vaginal) or antibiotics in the last 30 days, or who had diseases that affected the immune system. 


\subsection{Statement}

All experiments and methods were performed per relevant guidelines and regulations. All experimental protocols were approved by The Ethics Committee of the CEUMA University, specifically vaginal secretion samples collection (and relevant protocols) (813.402/2014). All subjects gave their informed consent for inclusion before they participated in the study, and all methods were carried out per the Declaration of Helsinki and guidelines/regulations of CEUMA Ethics Committee.

\subsection{Isolation and Identification of Vaginal Microorganisms}

Cervicovaginal sampling was performed using sterile swabs, which were immersed in sterile tubes containing BHI (Brain Heart Infusion; Difco Laboratories Inc., Detroit, MI, USA) or MRS (Man, Rogosa, and Sharpe broth; Difco, Detroit, MI, USA). Samples in BHI and MRS were placed at $37^{\circ} \mathrm{C}$ for $24 \mathrm{~h}$ and then seeded in MRS agar and SDA medium (Sabouraud Dextrose Agar; Difco Laboratories Inc., Detroit, MI, USA) for $48 \mathrm{~h}$. MRS agar plates were incubated under anaerobic conditions for Lactobacillus spp. isolation (Anaerobic System, Probac LTD, São Paulo, Brazil). SDA was used for Candida spp. isolation. A polymerase chain reaction (PCR) with multiple specific primers (multiplex PCR) was used for yeast identification (Supplementary Material S1) and partial sequencing of $16 \mathrm{~S}$ subunit rDNA (Supplementary Material S2) for Lactobacillus identification.

In addition to clinical isolates, reference strains were also included in this study (Supplementary Material S3).

\subsection{Antagonism Assay}

The antagonism assay was performed by the overlay method [31]. Cultures of Lactobacillus spp. were incubated under anaerobic conditions at $37^{\circ} \mathrm{C}$ for $24 \mathrm{~h}$ in MRS broth supplemented with $0.25 \%$ L-cysteine (MRS-CYS, Sigma-Aldrich, St. Louis, Missouri, USA). Bacterial samples were standardized at 0.1 at $\mathrm{OD}_{600 \mathrm{~nm}}$, and then $10 \mu \mathrm{L}$ of each sample was plated on MRS-CYS agar and incubated under the same conditions. After this period, a $2 \mathrm{~mm}$ layer of SDA was added, and the C. albicans standard inoculum $\left(1 \times 10^{7}\right.$ cells $\left./ \mathrm{mL}\right)$ was seeded on top. Petri dishes were incubated at $37^{\circ} \mathrm{C}$ for $24 \mathrm{~h}$ under aerobic conditions, and the subsequent measurements for zones of inhibition were taken.

\subsection{BS Production by Lactobacillus Spp.}

Initially, a small-scale culture of all Lactobacillus spp. was carried out to determine bacteria capable of producing BSs. Once those bacteria were identified, large-scale production of BS was carried out [53]. First, a colony isolated from each strain was added to $10 \mathrm{~mL}$ of MRS-CYS broth and incubated for $16 \mathrm{~h}$ at $37^{\circ} \mathrm{C}$ under anaerobic conditions. Then, a $4 \mathrm{~mL}$ aliquot was inoculated into $400 \mathrm{~mL}$ of MRS-CYS and incubated (anaerobic conditions, $48 \mathrm{~h}, 37^{\circ} \mathrm{C}$ ) for large-scale BS production. After the incubation period, a centrifugation step $\left(10,000 \times g, 5 \mathrm{~min}\right.$ at $\left.10^{\circ} \mathrm{C}\right)$ was used to harvest the cells, which were then washed and suspended in PBS solution (phosphate-buffered saline; $\mathrm{pH} 7 ; 15 \mathrm{~mL}$ of PBS for each $100 \mathrm{~mL}$ of culture). The suspension was kept at room temperature for $2 \mathrm{~h}$ with gentle stirring for biosurfactant release and then centrifuged $(1904 \times g$ for $15 \mathrm{~min})$. The supernatant was collected, filtered using a $0.22 \mathrm{~mm}$-pore-size filter (Merck KGaA, Darmstadt, Germany), lyophilized, and stored at $-20^{\circ} \mathrm{C}$. During the $48 \mathrm{~h}$ incubation period, aliquots were removed every $12 \mathrm{~h}$ for a dry-weight measurement, an $\mathrm{OD}_{640} \mathrm{~nm}$ check, and drop-collapse and emulsifying activity tests.

\subsubsection{Emulsifying Activity Determination}

Using either toluene or hexane as the hydrophobic substrate, the emulsifying activity $\left(\mathrm{E}_{24}\right)$ was measured to confirm BS production [35]. Two milliliters of toluene or hexane were added to an equal volume of sample and then vortexed at high speed for $2 \mathrm{~min}$ and incubated for $24 \mathrm{~h}$ at room temperature. Emulsification indices $\left(\mathrm{E}_{24}, \%\right)$ were the percentage of the height of the emulsifying layer $(\mathrm{mm})$ divided by the height of the total layer $(\mathrm{mm})$. 


\subsubsection{Dry Weight and $\mathrm{OD}_{640 \mathrm{~nm}}$ Measurements}

For dry-weight evaluation, an empty microtube was first weighed, and then $1 \mathrm{~mL}$ of sample was added. Microtubes were centrifuged, and the cells were dried at $60^{\circ} \mathrm{C}$ and weighed again. Dry-weight values were obtained from the equation,

$$
d w=M f-M i
$$

where $d w$ was the dry weight (g), $M f$ was the final weight of the microtube (g), and $M i$ was the initial weight of the microtube $(\mathrm{g})$.

Biomass values were recorded for all samples during the 12, 24, 36, and $48 \mathrm{~h}$ culture intervals by measuring the optical density of each culture at $640 \mathrm{~nm}$ using a spectrophotometer (Biotek, Goiânia, Brazil).

\subsubsection{Drop-Collapse Method}

A drop-collapse test was performed to verify whether BSs were able to reduce the surface tension (ST) between an aqueous solution and hydrophobic surfaces. Tests were performed in triplicate, and PBS was used as a control following recommendations [35]. Ten microliters of BS were added to a polystyrene plate well, and the spreading/flattening of the droplet on the polystyrene surface was monitored. The droplet was allowed to dry, and the diameter of the dried droplet was recorded.

\subsubsection{ST Determination}

BS ST values were measured by the plate method using a KRUSS tensiometer (K10T model, KRUSS, Hamburg, Germany) at room temperature to determine the relationship between BS concentration and ST. First, LAB cells were recovered by centrifugation $\left(10,000 \times g, 10 \mathrm{~min}, 4^{\circ} \mathrm{C}\right)$, then washed twice with PBS and resuspended in PBS. To calibrate the tensiometer, the ST measure was performed twice with distilled water. All ST measurements were performed in triplicate and averaged. Sterile PBS was used as a control.

\subsection{Selection of C. albicans Biofilm Producers}

Yeast Nitrogen Base (YNB) standardized inoculum $\left(200 \mu \mathrm{L} ; 1 \times 10^{7}\right.$ cells $\left./ \mathrm{mL}\right)$ and $100 \mathrm{mM}$ glucose were added to 96-well flat-bottom microplates. The test was performed with eight replicates, and the wells, containing only culture medium, were used as controls. Microplates were incubated for $90 \mathrm{~min}$ (adhesion period). Cells were washed with PBS, followed by the addition of $200 \mu \mathrm{L}$ of fresh medium and subsequent incubation for $48 \mathrm{~h}$ at $37^{\circ} \mathrm{C}$ under aerobic conditions. The culture medium was changed every $24 \mathrm{~h}$. For biofilm quantification, the medium was removed, and wells were washed with PBS. Cells were fixed with $200 \mu \mathrm{L}$ of $80 \%$ ethanol for $15 \mathrm{~min}$. The ethanol was removed, and plates were dried at room temperature and stained with $200 \mu \mathrm{L}$ of crystal violet (2\%) for $20 \mathrm{~min}$. PBS wash removed any excess stain. Crystal violet bound to the adherent microorganisms was resolubilized with $150 \mu \mathrm{L}$ glacial acetic acid solution (33\%) added to each well, and $150 \mu \mathrm{L}$ of the resultant mixture was transferred to new microplates. Microplate absorbance was measured at $550 \mathrm{~nm}$ [52].

\subsection{BS Interference on C. albicans Adhesion}

Two hundred microliters of each crude $48 \mathrm{~h}$ BS in PBS $(5 \mathrm{mg} / \mathrm{mL})$ were added to 96 -well microplate. The wells, containing only PBS, were used as controls. After $16 \mathrm{~h}$ of incubation at $4{ }^{\circ} \mathrm{C}$, microplates were washed twice with PBS. Then, a $200 \mu \mathrm{L}$ aliquot of yeast suspension $\left(0.38\right.$ at $\left.\mathrm{OD}_{550 \mathrm{~nm}}\right)$ was added and incubated for $4 \mathrm{~h}$ at $4{ }^{\circ} \mathrm{C}$. Tests were performed in triplicate on two different occasions. Wells were washed three times with PBS and then stained with crystal violet (Section 4.6). Attached cells were quantified using a microplate reader (Biotek, Goiânia, Brazil) at $550 \mathrm{~nm}$. Adhesion inhibition percentages for various BSs for each microorganism were determined as: 


$$
\% \text { Adhesion Inhibition }=\left(1-\left(\mathrm{A}_{\mathrm{BS}}\right) / \mathrm{A}_{0}\right) \times 100
$$

where $\mathrm{A}_{\mathrm{BS}}$ was the absorbance of the well treated with $\mathrm{BS}$, and $\mathrm{A}_{0}$ was the absorbance of the control well without BS [25].

\subsection{BS Interference on C. albicans Biofilm Formation}

Assays were performed under both pre-coating and co-incubation conditions [52]. In the pre-coating experiments, prior sensitization of the 96-well microplate was made by adding $200 \mu \mathrm{L}$ of crude $48 \mathrm{~h}$ BS in PBS $(5 \mathrm{mg} / \mathrm{mL})$ and incubating for $24 \mathrm{~h}$ at $37^{\circ} \mathrm{C}$. The wells, containing only water, were used as a control. Plates were washed twice with PBS. C. albicans inoculum $\left(200 \mu \mathrm{L} ; 0.38\right.$ at $\left.\mathrm{OD}_{550 \mathrm{~nm}}\right)$ was added, and microplates were incubated at $37^{\circ} \mathrm{C}$ for $3 \mathrm{~h}$. Wells were washed twice with PBS, and $200 \mu \mathrm{L}$ of fresh medium was added. Wells were incubated for $48 \mathrm{~h}$ at $37^{\circ} \mathrm{C}$, and the medium was changed every $24 \mathrm{~h}$.

In co-incubation experiments, C. albicans inoculum and BS were placed together in the wells in a 1:1 ratio and were incubated for $3 \mathrm{~h}$ under the same conditions as the previous test. After the washing process, wells were again filled with new medium and BS in the same ratio. Incubation conditions were maintained. Biofilm production was quantified as in Section 4.6.

Both tests were performed with three replicates and a control with no BS interference. For interpretation, the absorbance of each well was measured at $550 \mathrm{~nm}$ and compared with that of the control well.

\subsection{Antifungal Susceptibility Testing}

Susceptibility profiles of $C$. albicans isolates were established in relation to itraconazole (ITC), fluconazole (FLC), and amphotericin B (AMB), according to CLSI (Clinical Laboratory Standard Institute) [54]. Diluted antifungals were incubated in 96-well microplates with $C$. albicans isolates $\left(2.5 \times 10^{3} \mathrm{CFU} / \mathrm{mL}\right)$ at $35^{\circ} \mathrm{C}$ for $48 \mathrm{~h}$. Vehicle (RPMI)-treated wells without fungal isolates were used as negative controls. All tests were performed in triplicate on three different occasions. The MIC (minimum inhibitory concentration) of each antifungal was considered the lowest concentration at which no fungal growth was observed. Breakpoints were those defined by CLSI [54]. C. albicans ATCC 90028 was used as a control.

\subsection{Statistical Analysis}

Data were analyzed by IBM SPSS Statistics 20 (2011). Initially, a chi-square test of independence $\left(\chi^{2}\right)$ was used to evaluate the association of Lactobacillus and Candida spp. present in the vaginal microbiota of healthy and VVC women. Subsequently, normality tests of all numerical variables (inhibition halo, biofilm, BS production, BS on adhesion, BS on biofilm) were performed using the Shapiro-Wilk test followed by parametric tests (ANOVA, Tukey, Dunnett, ANCOVA, and Pearson's correlation). The effect of Lactobacillus spp. was evaluated by ANOVA. In all tests, the level of significance $(\alpha)$ was $5 \%$.

\section{Conclusions}

In conclusion, this study showed Lactobacillus strains with significant anti-Candida activity by inhibiting the growth of vaginal isolates. Some Lactobacillus strains produced BSs with high emulsifying indexes. Lactobacillus spp. produced BSs that exhibited considerable anti-adhesion and antibiofilm activities against $C$. albicans. Although the BSs in this study were not characterized, the results were promising and indicated future medical applications for analyzed BSs in the prevention and treatment of Candida infections. We highlighted the clinical isolate L. gasseri Lg1 and L. paracasei Lp11, both from vaginal secretions of asymptomatic patients, as promising sources of medically applicable BSs. 
Supplementary Materials: The following are available online at http://www.mdpi.com/2076-0817/8/3/150/s1, Supplementary Material S1: Describe the employed methodology for Candida spp. identification by multiplex PCR, Table S1: PCR multiplex primer sequences for Candida spp. identification, Supplementary Material S2: Describe the identification of Lactobacillus isolates by partial sequencing of $16 \mathrm{~S}$ subunit rDNA, Supplementary Material S3: Lists the reference strains used in this work.

Author Contributions: Conceptualization, C.I.d.S., C.A.M., C.D.L.C., and Y.R.F.; methodology, C.I.d.S., A.S.M., E.B.M., C.D.L.C., Y.R.F., B.O.M., and V.L.S.; software, S.G.M. and M.R.Q.B.; validation, C.I.d.S., C.A.M., and V.M.-N.; formal analysis, S.G.M. and R.A.H.; investigation, C.I.d.S., C.D.L.C., Y.R.F., and A.S.M.; resources, C.A.M. and V.M.-N.; data curation, C.A.M.; writing-original draft preparation, C.I.d.S., C.A.M., and V.M.-N.; writing-review and editing, C.A.M. and V.M.-N.; supervision, C.A.M., V.M.-N., and A.S.M.; project administration, C.I.d.S., C.A.M., and V.M.-N.

Funding: This research received no external funding.

Acknowledgments: C.I.S. and Y.R.F. are thankful to the Fundação de Amparo à Pesquisa e Desenvolvimento Científico do Maranhão (FAPEMA) for providing, respectively, a Masters and Scientific Initiation scholarships.

Conflicts of Interest: The authors declare no conflict of interest.

\section{References}

1. Larsen, B.; Monif, G.R.G. Understanding the Bacterial Flora of the Female Genital Tract. Clin. Infect. Dis. 2001, 32, e69-e77. [CrossRef] [PubMed]

2. Parolin, C.; Marangoni, A.; Laghi, L.; Foschi, C.; Nahui Palomino, R.A.; Calonghi, N.; Cevenini, R.; Vitali, B. Isolation of Vaginal Lactobacilli and Characterization of Anti-Candida Activity. PLoS ONE 2015, 10, e0131220. [CrossRef] [PubMed]

3. Sobel, J.D. Vulvovaginal candidosis. Lancet 2007, 369, 1961-1971. [CrossRef]

4. Xie, H.Y.; Feng, D.; Wei, D.M.; Mei, L.; Chen, H.; Wang, X.; Fang, F. Probiotics for vulvovaginal candidiasis in non-pregnant women. Cochrane Database Syst. Rev. 2017, 11, CD010496. [CrossRef] [PubMed]

5. Holzer, I.; Farr, A.; Kiss, H.; Hagmann, M.; Petricevic, L. The colonization with Candida species is more harmful in the second trimester of pregnancy. Arch. Gynecol. Obstet. 2017, 295, 891-895. [CrossRef] [PubMed]

6. Sobel, J.D. Recurrent vulvovaginal candidiasis. Am. J. Obstet. Gynecol. 2016, 214, 15-21. [CrossRef] [PubMed]

7. Alizadeh, M.; Kolecka, A.; Boekhout, T.; Zarrinfar, H.; Ghanbari Nahzag, M.A.; Badiee, P.; Rezaei-Matehkolaei, A.; Fata, A.; Dolatabadi, S.; Najafzadeh, M.J. Identification of Candida species isolated from vulvovaginitis using matrix assisted laser desorption ionizationtime of flight mass spectrometry. Curr. Med. Mycol. 2017, 3, 21-25. [CrossRef]

8. Nejat, Z.A.; Farahyar, S.; Falahati, M.; Khozani, M.A.; Hosseini, A.F.; Faiazy, A.; Ekhtiari, M.; Hashemi-Hafshenjani, S. Molecular Identification and Antifungal Susceptibility Pattern of Non-albicans Candida Species Isolated from Vulvovaginal Candidiasis. Iran. Biomed. J. 2018, 22, 33-41. [CrossRef]

9. Alves, M.B.; Silva, I.M.O.; Santos, C.I.; França, Y.R.; Oliveira, S.K.R.; Monteiro, S.G.; Monteiro, C.A. Prevalence of Candida spp. from samples of vaginal secretion and its relationship to factors associated with vulvovaginitis. Rev. Investig. Bioméd. 2015, 7, 58-68. [CrossRef]

10. Gonçalves, B.; Ferreira, C.; Alves, C.T.; Henriques, M.; Azeredo, J.; Silva, S. Vulvovaginal candidiasis: Epidemiology, microbiology and risk factors. Crit. Rev. Microbiol. 2016, 42, 905-927. [CrossRef]

11. Ishida, K.; Ueda-Yamaguchi, M.; Ogatta, S.F.Y.; Ueda-Nakamura, T.; Svidizinski, T.I.E.; Nakamura, C.V. Characterization of Candida spp. isolated from vaginal fluid: Identification, antifungal susceptibility, and virulence profile. Acta S. Health Sci. 2013, 35, 1-8. [CrossRef]

12. Siddiqi, R.; Mendiratta1, D.K.; Rukadikar, A.; Gadre, S. Study of Virulence Markers and Antifungal Susceptibility by Vitek-2 in Various Candida Species Isolated from Cases of Vulvovaginal Candidiasis. Int. J. Curr. Microbiol. App. Sci. 2017, 6, 3593-3605. [CrossRef]

13. Sherry, L.; Kean, R.; McKloud, E.; O’Donnell, L.E.; Metcalfe, R.; Jones, B.L.; Ramage, G. Biofilms formed by isolates from recurrent vulvovaginal candidiasis patients are heterogeneous and insensitive to fluconazole. Antimicrob. Agents Chemother. 2017, 61, e01065-e01117. [CrossRef] [PubMed]

14. Ravel, J.; Gajer, P.; Abdo, Z.; Schneider, G.M.; Koenig, S.S.; McCulle, S.L.; Karlebach, S.; Gorle, R.; Russell, J.; Tacket, C.O.; et al. Vaginal microbiome of reproductive-age women. Proc. Natl. Acad. Sci. USA 2011, 108, 4680-4687. [CrossRef] [PubMed] 
15. Pascual, L.M.; Daniele, M.B.; Ruiz, F.; Giordano, W.; Pájaro, C.; Barberis, L. Lactobacillus rhamnosus L60, a potential probiotic isolated from the human vagina. J. Gen. Appl. Microbiol. 2008, 54, 141-148. [CrossRef] [PubMed]

16. Reid, G.; Younes, J.A.; Vander Mei, H.C.; Gloor, G.B.; Knight, R.; Busscher, H.J. Microbiota restoration: Natural and supplemented recovery of human microbial communities. Nat. Rev. Microbiol. 2011, 9, 27-38. [CrossRef] [PubMed]

17. Borges, S.; Silva, J.; Teixeira, P. The role of lactobacilli and probiotics in maintaining vaginal health. Arch. Gynecol. Obstet. 2014, 289, 479-489. [CrossRef] [PubMed]

18. Babula, O.; Lazdane, G.; 2 Kroica, J.; Linhares, I.M.; Ledger, W.J.; Witkin, S.S. Frequency of Interleukin-4 (IL-4) 589 Gene Polymorphism and Vaginal Concentrations of IL-4, Nitric Oxide, and Mannose-Binding Lectin in Women with Recurrent Vulvovaginal Candidiasis. Clin. Infect. Dis. 2005, 40, 1258-1262. [CrossRef]

19. Rodrigues, L.R.; Teixeira, J.A.; Van der Mei, H.C.; Oliveira, R. Physicochemical and functional characterization of a biosurfactant produced by Lactobacillus lactis 53. Colloids Surf. B Biointerfaces 2006, 49, 79-86. [CrossRef]

20. Hill, C.; Guarner, F.; Reid, G.; Gibson, G.R.; Merenstein, D.J.; Pot, B.; Morelli, L.; Canani, R.B.; Flint, H.J.; Salminen, S.; et al. Expert consensus document. The International Scientific Association for Probiotics and Prebiotics consensus statement on the scope and appropriate use of the term probiotic. Nat. Rev. Gastroenterol. Hepatol. 2014, 11, 506-514. [CrossRef]

21. Rodrigues, L.; Van der Mei, H.; Teixeira, J.A.; Oliveira, R. Biosurfactant from Lactococcus lactis 53 inhibits microbial adhesion on silicone rubber. Appl. Microbiol. Biotechnol. 2004, 66, 306-311. [CrossRef] [PubMed]

22. Rodrigues, L.; Banat, I.M.; Teixeira, J.; Oliveira, R. Biosurfactants: Potential applications in medicine. J. Antimicrob. Chemother. 2006, 57, 609-618. [CrossRef] [PubMed]

23. Gudiña, E.J.; Rocha, V.; Teixeira, J.A.; Rodrigues, L.R. Antimicrobial and antiadhesive properties of a biosurfactant isolated from Lactobacillus paracasei ssp. paracasei A20. Lett. Appl. Microbiol. 2010, 50, 419-424. [CrossRef]

24. Thavasi, R.; Jayalakshmi, S.; Banat, I.M. Application of biosurfactant produced from peanut oil cake by Lactobacillus delbrueckii in biodegradation of crude oil. Bioresour. Technol. 2011, 102, 3366-3372. [CrossRef] [PubMed]

25. Sharma, D.; Saharan, B.S.; Chauhan, N.; Procha, S.; Lal, S. Isolation and functional characterization of novel biosurfactant produced by Enterococcus faecium. Springer Plus 2015, 4, 1. [CrossRef] [PubMed]

26. Nitschke, M.; Silva, S.S.E. Recent food applications of microbial surfactants. Crit. Rev. Food Sci. Nutr. 2017, 58, 631-638. [CrossRef] [PubMed]

27. Reid, G.; Zalai, C.; Gardiner, G. Urogenital lactobacilli probiotics, reliability, and regulatory issues. J. Dairy Sci. 2001, 84, E164-E169. [CrossRef]

28. Saharan, B.S.; Sahu, R.K.; Sharma, D. A review on biosurfactants: Fermentation, current developments and perspectives. Genet. Eng. Biotechnol. J. 2011, 2011, 1-14.

29. Shekhar, S.; Sundaramanickam, A.; Balasubramanian, T. Biosurfactant Producing Microbes and their Potential Applications: A Review. Crit. Rev. Environ. Sci. Technol. 2014, 45, 1522-1554. [CrossRef]

30. Santos, D.K.; Rufino, R.D.; Luna, J.M.; Santos, V.A.; Salgueiro, A.A.; Sarubbo, L.A. Synthesis and evaluation of biosurfactant produced by Candida lipolytica using animal fat and corn steep liquor. J. Pet. Sci. Eng. 2013, 105, 43-50. [CrossRef]

31. Chew, S.Y.; Cheah, Y.K.; Seow, H.F.; Sandai, D.; Than, L.T.L. Probiotic Lactobacillus rhamnosus GR-1 and Lactobacillus reuteri RC-14 exhibit strong antifungal effects against vulvovaginal candidiasis-causing Candida glabrata isolates. J. Appl. Microbiol. 2015, 118, 1180-1190. [CrossRef] [PubMed]

32. Wang, S.; Wang, Q.; Yang, E.; Yan, L.; Li, T.; Zhuang, H. Antimicrobial Compounds Produced by Vaginal Lactobacillus crispatus Are Able to Strongly Inhibit Candida albicans Growth, Hyphal Formation and Regulate Virulence-related Gene Expressions. Front. Microbiol. 2017, 8, 564. [CrossRef] [PubMed]

33. Carmo, M.S.; Noronha, F.M.; Arruda, M.O.; Costa, Ê.P.; Bomfim, M.R.; Monteiro, A.S.; Ferro, T.A.; Fernandes, E.S.; Girón, J.A.; Monteiro-Neto, V. Lactobacillus fermentum ATCC 23271 displays in vitro inhibitory activities against Candida spp. Front. Microbiol. 2016, 7, 1722. [CrossRef] [PubMed]

34. Gudiña, E.J.; Fernandes, E.C.; Teixeira, J.A.; Rodrigues, L.R. Antimicrobial and anti-adhesive activities of cell-bound biosurfactant from Lactobacillus agilis CCUG31450. RSC Adv. 2015, 5, 90960-90968. [CrossRef] 
35. Tahmourespour, A.; Salehi, R.; Kermanshahi, R.K. Lactobacillus acidophilus-derived biosurfactant effect on $g t f \mathrm{~B}$ and $g t f \mathrm{C}$ expression level in Streptococcus mutans biofilm cells. Braz. J. Microbiol. 2011, 42, 330-339. [CrossRef] [PubMed]

36. Al Kassaa, I.; Hamze, M.; Hober, D.; Chihib, N.E.; Drider, D. Identification of vaginal lactobacilli with potential probiotic properties isolated from women in North Lebanon. Microbial. Ecol. 2014, 67, 722-734. [CrossRef] [PubMed]

37. Ceresa, C.; Tessarolo, F.; Caola, I.; Nollo, G.; Cavallo, M.; Rinaldi, M.; Fracchia, L. Inhibition of Candida albicans adhesion on medical-grade silicone by a Lactobacillus-derived biosurfactant. J. Appl. Microbiol. 2015, 118, 1116-1125. [CrossRef] [PubMed]

38. Morais, I.M.C.; Cordeiro, A.L.; Teixeira, G.S.; Domingues, V.S.; Nardi, R.M.D.; Monteiro, A.S.; Alves, R.J.; Siqueira, E.P.; Santos, V.L. Biological and physicochemical properties of biosurfactants produced by Lactobacillus jensenii P6A and Lactobacillus gasseri P65. Microb. Cell Fact. 2017, 16, 155. [CrossRef]

39. Patowary, K.; Patowary, R.; Kalita, M.C.; Deka, S. Characterization of Biosurfactant Produced during Degradation of Hydrocarbons Using Crude Oil as Sole Source of Carbon. Front. Microbiol. 2017, 8, 279. [CrossRef]

40. Madhu, N.; Prapulla, S.G. Evaluation and functional characterization of a biosurfactant produced by Lactobacillus plantarum CFR 2194. Appl. Biochem. Biotechnol. 2014, 172, 1777-1789. [CrossRef]

41. Juwarkar, A.A.; Nair, A.; Dubey, K.V.; Singh, S.K.; Devotta, S. Biosurfactant technology for remediation of cadmium and lead contaminated soils. Chemosphere 2007, 68, 1996-2002. [CrossRef] [PubMed]

42. Banat, I.M.; Franzetti, A.; Gandolfi, I.; Bestetti, G.; Martinotti, M.G.; Fracchia, L.; Smyth, T.J.; Marchant, R. Microbial biosurfactants production, applications and future potential. Appl. Microbial. Biotechnol. 2010, 87, 427-444. [CrossRef] [PubMed]

43. Gudiña, E.J.; Teixeira, J.A.; Rodrigues, L.R. Biosurfactant-Producing Lactobacilli: Screening, Production Profiles, and Effect of Medium Composition. Appl. Environ. Soil Sci. 2011. [CrossRef]

44. Monteiro, A.S.; Miranda, T.T.; Lula, I.; Denadai, Â.M.; Sinisterra, R.D.; Santoro, M.M.; Santos, V.L. Inhibition of Candida albicans CC biofilms formation in polystyrene plate surfaces by biosurfactant produced by Trichosporon montevideense CLOA72. Colloids Surf. B Biointerfaces 2011, 84, 467-476. [CrossRef] [PubMed]

45. Neu, T.R.; Marshall, K.C. Bacterial polymers: Physicochemical aspects of their interactions at interfaces. J. Biomater. Appl. 1990, 5, 107-133. [CrossRef] [PubMed]

46. Maingault, M. Utilization of Sophorolipids as Therapeutically Active Substances or Cosmetic Products, in Particular for the Treatment of the Skin. U.S. Patent No. 5,981,497, 29 January 1999.

47. Stipcevic, T.; Piljac, A.; Piljac, G. Enhanced healing of full-thickness burn wounds using di-rhamnolipid. Burns 2006, 32, 24-34. [CrossRef] [PubMed]

48. Piljac, A.; Stipčević, T.; Piljac-Žegarac, J.; Piljac, G. Successful treatment of chronic decubitus ulcer with $0.1 \%$ dirhamnolipid ointment. J. Cutan. Med. Surg. 2008, 12, 142-146. [CrossRef] [PubMed]

49. Vilela, S.F.; Barbosa, J.O.; Rossoni, R.D.; Santos, J.D.; Prata, M.C.; Anbinder, A.L.; Jorge, A.O.; Junqueira, J.C. Lactobacillus acidophilus ATCC 4356 inhibits biofilm formation by C. albicans and attenuates the experimental candidiasis in Galleria mellonella. Virulence 2015, 6, 29-39. [CrossRef] [PubMed]

50. Meylheuc, T.; Methivier, C.; Renault, M.; Herry, J.M.; Pradier, C.M.; Bellon-Fontaine, M.N. Adsorption on stainless steel surfaces of biosurfactants produced by gram-negative and gram-positive bacteria: Consequence on the bioadhesive behavior of Listeria monocytogenes. Colloids Surf. B Biointerfaces 2006, 52, 128-137. [CrossRef] [PubMed]

51. Velraeds, M.M.; Van de Belt-Gritter, B.; Van der Mei, H.C.; Reid, G.; Busscher, H.J. Interference in initial adhesion of uropathogenic bacteria and yeasts to silicone rubber by a Lactobacillus acidophilus biosurfactant. J. Med. Microbiol. 1998, 47, 1081-1085. [CrossRef] [PubMed]

52. Fracchia, L.; Cavallo, M.; Allegrone, G.; Martinotti, M.G.A. Lactobacillus-derived biosurfactant inhibits biofilm formation of human pathogenic Candida albicans biofilm producers. Appl. Microbiol. Biotechnol. 2010, 2, 827-837.

53. Gudiña, E.J.; Teixeira, J.A.; Rodrigues, L.R. Isolation and functional characterization of a biosurfactant produced by Lactobacillus paracasei. Colloids Surf. B Biointerfaces 2010, 76, 298-304. [CrossRef] [PubMed]

54. Clinical and Laboratory Standards Institute [CLSI]. M27-A3 Reference method for broth dilution antifungal susceptibility testing of yeast; approved standard- third edition. Clin. Lab. Stand. Instit. 2008, 28, 6-12.

(C) 2019 by the authors. Licensee MDPI, Basel, Switzerland. This article is an open access article distributed under the terms and conditions of the Creative Commons Attribution (CC BY) license (http://creativecommons.org/licenses/by/4.0/). 